\title{
CRÔNICAS DA VIDA NA CIDADE: O COTIDIANO DA POLÍTICA NAS CHARGES DA REVISTA ILUSTRADA (1892-1898) ${ }^{1}$
}

\author{
Marcelo de Souza Magalhães \\ Universidade do Estado do Rio de Janeiro
}

Publicado em 1926, o livro História da cidade do Rio de Janeiro, do geógrafo Delgado de Carvalho, é dedicado à memória de Pereira Passos. No prefácio, o autor afirma tê-lo escrito para suprir a falta de um "compêndio moderno, destinado a facilitar às professoras públicas a coleta de dados esparsos" (CARVALHO, 1990:19) acerca da História do Distrito Federal, já que tal ponto havia sido incluído no programa do ensino do quarto ano primário. Logo, esse foi um livro escrito para auxiliar as professoras no trabalho de formação dos alunos que passavam pelos bancos escolares da capital federal, nos anos 1920 .

Por ser um livro pioneiro, considerando seu tema e público-alvo, torna-se interessante analisar as escolhas feitas pelo autor para compô-lo. Retornando ao prefácio, verifica-se a intenção de não ser um livro de história administrativa, de tipo tradicional:

\begin{abstract}
A história do Rio de Janeiro não é a história de seus governadores, de seus vice-reis, de seus monarcas, presidentes e prefeitos: algumas datas célebres, alguns nomes importantes podem e devem marcar etapas na sucessão dos tempos, no desenvolver dos acontecimentos; mas os assuntos capitais desta história são as condições de vida dos próprios cariocas, em diferentes épocas, suas tradições, seus costumes, seus usos, suas necessidades, suas festas (CARVALHO, 1990:21).
\end{abstract}

Apesar da ressalva feita, a divisão dos capítulos privilegia as mudanças no campo político-administrativo: "A fundação da cidade", "A capital do sul", "O 180 século", "A capital dos vice-reis", "A sede da monarquia portuguesa", "O município neutro", "A capital federal" e, por fim, "O governo e administração".

Acompanhando as mudanças políticas ocorridas na cidade, desde sua fundação no século XVI, Delgado de Carvalho cita "nomes que podem servir de

\footnotetext{
${ }^{1 *}$ Uma versão da parte inicial deste texto foi publicada em Magalhães (2007). A parte sobre a Revista Ilustrada é uma versão do quarto capítulo de minha tese de doutorado, defendida no Programa de Pós-graduação em História da Universidade Federal Fluminense em fevereiro de 2004, intitulada Ecos da política: a capital federal, 1892-1902.
}

URBANA, ano 2, no 2, 2007, Dossiê: Cidade, Imagem, História e Interdisciplinaridade. 
exemplos às gerações", ou seja, "grandes vultos" da História do Rio de Janeiro: Salvador de Sá, Gomes Freire, Lavradio, Luís de Vasconcelos, Fernandes Viana, Pedro II, Osvaldo Cruz e Pereira Passos.

O fato de o autor dedicar a Passos um livro sobre o Rio, sobretudo quando escrito para um público escolar, é extremamente significativo. Nele, como em outros livros, a memória construída sobre a administração do prefeito Pereira Passos (1902-1906) parece eclipsar todas as demais, principalmente aquelas que assumiram a chefia do Poder Executivo municipal, no início da República, ou seja, entre 1892 e 1902. A tais administrações é dedicado um espaço muito pequeno nos livros, quase sempre composto de comentários sobre a grande instabilidade do período, a crise financeira por que se passava e a impossibilidade de grandes realizações. Vencida essa década, logo ganham destaque as realizações da gestão Passos, intitulada sugestivamente por Delgado de Carvalho de "A Era dos Melhoramentos".

Trabalhos como o de Noronha Santos (1945) - Acerca da organização municipal e dos prefeitos do Distrito Federal - e de José de Oliveira Reis (1977) O Rio de Janeiro e seus prefeitos -, também dedicam um bom espaço à administração de Passos, em detrimento das anteriores. Para se ter uma noção da diferença de tratamento, basta citar que, no livro de Oliveira Reis, a administração de Pereira Passos ocupa dezesseis páginas; já as anteriores, de 1889 a 1902, ocupam apenas cinco páginas. Mas no caso do engenheiro Oliveira Reis, é justo fazer a ressalva de que seu livro tinha, como objetivo principal, acompanhar as modificações urbanísticas ocorridas ao longo da história da cidade do Rio de Janeiro. Logo, o período do governo Passos adquire uma grande importância, por ser o momento em que diversas obras estavam sendo implementadas na cidade, tanto pelo governo federal, quanto pela Prefeitura. Essa é a época da abertura da avenida Central, Beira-Mar, Rodrigues Alves, dentre outras; do alargamento de diversas ruas, como a da Carioca e da Assembléia; das obras do cais do porto etc.

Na historiografia acerca do Rio de Janeiro, que cresceu no final da década de 1980, também é possível perceber um certo esquecimento das administrações anteriores a de Pereira Passos. Numa das vertentes dessa historiografia, o interesse pelas administrações municipais entrava sempre como coadjuvante de um tema maior que era o da questão urbana. Grande parte das pesquisas

URBANA, ano 2, no 2, 2007, Dossiê: Cidade, Imagem, História e Interdisciplinaridade. 
produzidas nos programas de pós-graduação em História da UFF (BODSTEIN, 1984, CARVALHO, 1984, ELIA, 1984, GANTOS, 1993 e ROCHA, 1995) e de Planejamento Urbano e Regional da UFRJ (BENCHIMOL, 1992, LAMARÃO, 1991, ALBERNAZ, 1985 e VAZ, 1985) tinha como objetivo analisar os projetos e as formas de intervenção dos poderes públicos no espaço urbano. Assim, a gestão de Pereira Passos tornou-se um ícone da forma autoritária como os poderes públicos intervinham no urbano, com vistas a excluir as classes populares das regiões centrais da cidade, deslocando-as para os subúrbios.

Tal vertente de estudos sobre o urbano ajudou a construir uma "outra" memória sobre a administração Passos, na contramão da "Era dos Melhoramentos". O historiador Oswaldo Porto Rocha (1995) qualificou o período como "A Era das Demolições", sinalizando o tipo de releitura feita por essa historiografia sobre Passos.

Numa outra linhagem dessa historiografia, estão os trabalhos produzidos por um grupo de pesquisadores ligados ao Centro de Estudos Históricos da Fundação Casa de Rui Barbosa. Um dos caminhos trilhados pelo grupo foi o de efetivamente pesquisar as instituições municipais no âmbito da capital federal. Daí surgiram os trabalhos sobre o Conselho de Intendência Municipal, de Ana Marta Rodrigues Bastos (1984), e sobre a Prefeitura municipal, de Elisabeth von der Weid (1984). Para Weid, o prefeito do Distrito Federal - por ser uma pessoa indicada pelo presidente da República e não pela população carioca, através do voto - é situado como uma figura de ligação entre o Executivo federal e o Conselho Municipal. Isto é, esperava-se da pessoa indicada para ocupar o cargo de Prefeito ser capaz de desempenhar o papel de intermediário entre os poderes federal e municipal. A autora ressalta que o fato de o prefeito ter correspondido ou não à expectativa de quem lhe delegou o poder foi decisivo para sua permanência no cargo.

Outra interpretação sobre a atuação dos prefeitos do Distrito Federal está presente no livro Os bestializados, de José Murilo de Carvalho (1987). A condição singular da cidade do Rio de Janeiro - acumulando duas instâncias de poder num mesmo espaço, capital federal e sede do município -, teria gerado um conflito de competências com relação à resolução dos problemas da cidade. Nessa disputa entre instâncias de poder, o governo federal teria conseguido despolitizar o poder

URBANA, ano 2, no 2, 2007, Dossiê: Cidade, Imagem, História e Interdisciplinaridade. 
municipal, tanto que o prefeito Pereira Passos, nomeado pelo presidente da República, governara ditatorialmente, com o Conselho Municipal fechado.

A imagem do prefeito como um interventor, absolutamente vinculado aos interesses do Executivo federal, é a que acaba por se consolidar a partir desse amplo conjunto de pesquisas. Nas palavras de Carvalho (1987:34): "Na verdade, o Rio republicano foi governado o tempo todo por interventores, que mais não eram os prefeitos nomeados".

Se o interesse pelo governo de Pereira Passos terminou por colocar à sombra as gestões anteriores dos prefeitos do Distrito Federal, o que dizer sobre a atuação dos intendentes - atuais vereadores - do Conselho Municipal? No caso do Poder Legislativo, o esquecimento é ainda maior, não havendo estudos na historiografia acerca do Rio de Janeiro sobre os primeiros anos dessa instituição. Na produção historiográfica em geral, o Conselho só entra em cena, justamente, no momento em que é fechado por seis meses, quando Pereira Passos assume a Prefeitura. Mais uma vez a presença de Passos, agora influenciando as interpretações sobre a casa legislativa. Assim, o Conselho que surge dessa interpretação é fraco, sendo incapaz de se rebelar contra as determinações do Executivo municipal e estando dissociado da representação dos cidadãos. O que se consagra é a existência de um fosso entre essa instituição e a cidade.

O meu trabalho de doutoramento (MAGALHÃES, 2004), ao lidar com uma ampla documentação - produzida, principalmente, pelos poderes municipais -, contribui para relativizar essas interpretações sobre o papel do prefeito do Distrito Federal e do Conselho Municipal.

Pelo discurso dos prefeitos no cerimonial de abertura das sessões legislativas municipais e pela atuação dos mesmos quando da oposição de vetos às resoluções do Conselho, verificou-se que as interpretações que simplificam suas ações, ao considerá-los como intermediários ou interventores, não se sustentam. Os prefeitos, não importando tanto a origem da delegação de seus poderes, atuaram de forma relativamente autônoma, por vezes indo de encontro aos interesses do governo da União.

Com relação à casa legislativa municipal, foi possível demonstrar dois pontos. O primeiro é que os membros do Conselho Municipal trabalhavam muito, produzindo uma quantidade considerável de projetos de lei, que versavam sobre problemas caros a população da cidade, ou, ao menos, a uma parte dela. 0

URBANA, ano 2, no 2, 2007, Dossiê: Cidade, Imagem, História e Interdisciplinaridade. 
segundo, relacionado ao anterior, é que tal instituição, longe de estar pairando no ar, possuía consistentes relações com a cidade e os seus cidadãos. As análises dos requerimentos, dos abaixo-assinados, das representações e das petições apresentadas ao Conselho, bem como das queixas do povo e das imagens presentes na Revista Ilustrada sustentam a afirmação anterior. ${ }^{2}$ Além disso, permitem dizer mais: entre 1892 e 1902, apesar das fraudes nas eleições, que sabemos ter existido na Primeira República, havia relações de representação política entre os intendentes e os habitantes da cidade. A instituição legislativa era reconhecida, ao menos em parte, pelos habitantes da cidade, como um lugar legítimo tanto para conseguir o que se requer dos poderes municipais, como para recorrer contra decisões tomadas pela Prefeitura e pelo Judiciário.

O argumento de que o Conselho Municipal mantinha relações de representação política com a cidade pode ser reforçado indo além das demandas formais apresentadas à Casa, via requerimentos, abaixo-assinados, petições e representações. Nesse caso, mesmo que em grande número, sempre se pode dizer que tais contatos eram parciais, não alcançando a maioria da população da cidade.

Além disso, as demandas exigiam dos seus autores força de vontade e capacidade de organização para formalizá-las. Essa força de vontade, de alguma forma também estava presente na coluna "Queixas do Povo", pois para apresentar a queixa era preciso ir à redação do Jornal do Brasil.

Tanto as demandas formais feitas ao Conselho, como as "queixas" presentes na coluna do Jornal do Brasil, versavam sobre temáticas similares, afeitas ao cotidiano de grande parte da população da cidade. Ou seja, os intendentes discutiam na casa legislativa problemas que, ao mesmo tempo, eram denunciados nos periódicos cariocas. Problemas esses relacionados, por exemplo,

\footnotetext{
${ }^{2}$ Através da comparação entre as temáticas dos projetos de lei e as temáticas presentes na coluna "Queixas do Povo" do Jornal do Brasil, verificou-se a preocupação dos intendentes em discutir e enfrentar os problemas que afligiam grande parte da população da cidade.
}

URBANA, ano 2, no 2, 2007, Dossiê: Cidade, Imagem, História e Interdisciplinaridade. 
ao abastecimento de alimentos e de água, à iluminação pública, à limpeza urbana e ao calçamento de ruas da cidade.

A imprensa, por conseguinte, era (como continua sendo) um valioso mediador entre população e políticos. As "queixas" eram uma das formas utilizadas, segundo o clássico recurso do "denunciar", escrevendo cartas aos jornais. Mas havia outras formas igualmente competentes para que o processo comunicativo entre representados e representantes se efetivasse. Uma dessas formas pode ser detectada através da análise das charges presentes na Revista Ilustrada sobre a política municipal. Entendendo que a crítica política, através do humor presente nas charges ${ }^{3}$, também era uma das formas de vocalizar os problemas da cidade e de encaminhar demandas da população em geral, torna-se valioso examinar tal linguagem visual para verificar como ela se aproximava das questões debatidas no Conselho Municipal.

Os números da Revista Ilustrada, entre 1892 e 1898, reservaram um grande espaço às charges relacionadas à política municipal no âmbito da capital federal. Acompanhá-las significa ter acesso a uma espécie de crônica dos acontecimentos políticos eleitos como dignos de serem caricaturados. Essa, digamos, crônica, é marcada pelo ato de fazer crítica política pela via do humor. Por utilizar a linguagem visual numa cidade com um número significativo de iletrados, certamente possuía grandes chances de alcançar um público amplo. Exatamente pelo fato de usar fartamente imagens, a Revista Ilustrada era, nessa época, um dos mais populares periódicos do Rio.

Fundada em 1876, a Revista Ilustrada teve vida longa, só deixando de circular em 1898, após vinte e dois anos. Logo, ela teve uma longevidade muito diferente de suas congêneres na imprensa carioca, quase todas com vida efêmera, não passando de poucos números. A Revista ${ }^{4}$ praticamente não teve concorrente a altura até o final do século XIX, dominando o campo da imprensa ilustrada na cidade do Rio de Janeiro. Entre 1876 e 1889, através da crítica política pela via da linguagem visual do humor, ela adquiriu um grande prestígio, colocando-se plenamente a favor tanto do fim da escravidão, como da instauração do regime republicano no Brasil. A crítica ao Império foi foco da

\footnotetext{
$3 \mathrm{Na}$ historiografia brasileira já existe um número de trabalhos considerável sobre humor e linguagem visual (charges e caricaturas), tais como: Silva (1990), Velloso (1996), Saliba (2002), Lustosa (2003), Teixeira (2001), Ribeiro (1988) e Belluzzo (1992).

${ }^{4}$ A Revista Ilustrada será denominada de Revista em algumas partes do texto.
}

URBANA, ano 2, no 2, 2007, Dossiê: Cidade, Imagem, História e Interdisciplinaridade. 
atenção da Revista por um bom tempo, através da produção de uma série de caricaturas de D. Pedro II. Nessa série, surge um monarca retratado como senil, quase sempre dormindo; logo, sendo incapaz de levar adiante o governo do Brasil (Cf. SCHWARCZ, 2000).

Após a Abolição e a instauração da República, a Revista alcançou a tiragem, quase sempre quinzenal, de quatro mil exemplares. De acordo com Herman Lima (1963), tal número jamais havia sido atingido por um jornal ilustrado na América do Sul, ainda mais levando em consideração o fato de ser um periódico regularmente distribuído não só na cidade do Rio, como nos demais cantos do país. Tempos depois, Monteiro Lobato, ao escrever um artigo sobre a história da caricatura no Brasil, analisa a importância da Revista Ilustrada fazendo referência ao fato dela ter atingido quase todo o território nacional:

Não havia casa em que não penetrasse a Revista, e tanto deliciava as cidades como as fazendas. Quadro típico de cor local era a do fazendeiro que chegava cansado da roça, apeava, entregava o cavalo ao negro, entrava, sentava-se na rede, pedia café à mulatinha e abria a Revista. Os desenhos acabados, muito ao sabor de sua cultura e gosto, desfiavam ante seus olhos os acontecimentos políticos da quinzena. O rosto do fazendeiro iluminava-se de saudáveis risos. 'É um danado este sujeito' - dizia ele de Agostini (LOBATO apud LIMA, 1963:119).

O caricaturista Ângelo Agostini (1843-1910) esteve à frente da Revista Ilustrada desde sua fundação até o ano de 1888. Natural da Itália, veio para o Brasil no ano de 1850, e tornou-se um dos desenhistas mais famosos do período, atuando, inicialmente, em São Paulo e, posteriormente, no Rio de Janeiro. Deixou a capital paulista após sofrer ameaças, motivadas pelo teor crítico presente na revista Cabrião, por ele fundada em 1866. Antes disso, trabalhou na revista Diabo Coxo, de 1864. No Rio de Janeiro atuou em diversas revistas, por vezes, como colaborador, outras vezes, como fundador: Arlequim (1867), Vida Fluminense (1868-1875), O Fígaro (1876-1878), O Mosquito (1869-1875), Dom Quixote (1895-1903), O Malho (1902-1954) e O Tico-Tico (1905-1959) (Belluzzo, 1992).

Segundo Herman Lima (1963:118), os desenhos de Agostini eram considerados de grande clareza, "uma clareza patente a todas as inteligências". Talvez, essa dita clareza, associada à abordagem de temas caros para parte

URBANA, ano 2, no 2, 2007, Dossiê: Cidade, Imagem, História e Interdisciplinaridade. 
considerável da população da cidade do Rio de Janeiro, ajude a compreender o sucesso de público da Revista Ilustrada.

Após 1888, devido ao retorno de Agostini para a Europa, o caricaturista Pereira Neto assumiu a direção da Revista Ilustrada, ficando a sua frente até 1898, quando ela deixou de circular. Pereira Neto, discípulo de Agostini, praticamente continuou o trabalho inaugurado pelo mestre na Revista.

Entre 1892 e 1898, apenas uma vez Pereira Neto assinou uma caricatura na Revista Ilustrada, as demais não possuem assinatura. O traço de Pereira Neto se confunde com o de Agostini, sendo quase impossível identificar a autoria das imagens. Ainda mais ao se levar em conta que Agostini continuou a colaborar, mesmo que esporadicamente, com a Revista Ilustrada.

A política municipal passou pela Revista, tanto através de temas extraordinários - eleições municipais, nomeação de prefeito e oposição de veto a uma resolução do Conselho - como de temas ordinários, relativos ao cotidiano da cidade - abastecimentos de carne e água, limpeza urbana, calçamento etc. Os temas ordinários, não só ocuparam o maior espaço na pauta de discussão dos poderes municipais como, provavelmente, também eram os que mais atraíam o interesse de grande parte da população da cidade.

Após a seleção de um conjunto de imagens relativas à vida política da cidade, a opção foi reuni-las em grupos de semelhanças, em função da presença de temas da política ordinária e da política extraordinária. A presença de tais temas nas charges da Revista Ilustrada serve para demonstrar que a discussão política não estava restrita ao espaço do Conselho Municipal. Os temas relevantes para a vida na cidade estavam presentes na imprensa e possuíam ressonância no interior das instituições políticas formais. Da mesma forma, temas caros para o Conselho e a Prefeitura circulavam para além do espaço institucional, alcançando as ruas, principalmente, através de imagens bem humoradas.

\section{Imagens da política extraordinária}

URBANA, ano 2, no 2, 2007, Dossiê: Cidade, Imagem, História e Interdisciplinaridade. 
A Revista Ilustrada permite acompanhar toda a celeuma ocorrida em torno da indicação do primeiro prefeito do Distrito Federal, Candido Barata Ribeiro. Após a sanção da Lei Orgânica de 1892, Floriano Peixoto, na ocasião, vice-presidente da República, adiou por demais a indicação da pessoa que assumiria a chefia do Executivo municipal. Ele só fez a nomeação, depois que Alfredo Barcellos, presidente do então eleito Conselho Municipal, assumiu o cargo interinamente. A demora gerou profunda discussão entre os políticos, podendo ser acompanhada pelas notícias dos principais jornais cariocas, como, por exemplo, O Paiz. A imprensa, nessa oportunidade, tanto cumpria o papel de especular sobre quem ocuparia o cargo, como o de pressionar Floriano a fazer a indicação. Além disso, naturalmente, informava o povo sobre o que acontecia. No final de 1892 e início de 1893, em três de seus números, a Revista tratou do assunto.

Em novembro, opinou na discussão presente na imprensa carioca em torno da demora na indicação. Na página final do no 653, encontramos a imagem de Floriano saindo de um barril, agachado na escuridão, meio tateante e segurando uma lanterna. Esse Floriano, vestido como mendigo, tal qual o filósofo grego Diógenes saindo de um barril com uma lanterna na mão, à procura de um homem digno, servia para ilustrar um tema que ocupava o mundo da política naquele momento, como demonstra a imagem a seguir:

URBANA, ano 2, no 2, 2007, Dossiê: Cidade, Imagem, História e Interdisciplinaridade. 
Imagem 1. Revista Ilustrada, no 653, 1892 - FCRB.

O número seguinte, já em dezembro, a Revista Ilustrada trouxe uma história em três quadros acerca da nomeação do prefeito. No primeiro, homens conversam especulando sobre os nomes possíveis para assumir o cargo de Prefeito. A legenda porta uma certa ambigüidade, mostrando, ao mesmo tempo, a imensa expectativa que existia em torno da demorada indicação e a polêmica ocorrida após o nome de Candido Barata Ribeiro ser revelado: "A nomeação do prefeito municipal também deu muito que falar: - Quem será? Quem será?". O quadro é uma barata - representação recorrente desse prefeito na Revista - em cima de uma montanha, com a legenda: "E afinal, desta vez surgiu da montanha, não o clássico ratinho, e sim uma barata". O último quadro mostra o prefeito numa situação não muito confortável dentro do Conselho Municipal, como se pode ver.

URBANA, ano 2, no 2, 2007, Dossiê: Cidade, Imagem, História e Interdisciplinaridade. 


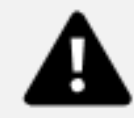

2. Revista Ilustrada, № 654, 1892 - FCRB.

A "sorte" mencionada na legenda provavelmente fazia referência ao seu passado na administração da cidade. Ao assumir a presidência do Conselho de Intendência Municipal, uma instituição provisória, Barata Ribeiro teve relações difíceis com os demais membros, também denominados intendentes. O conflito entre eles foi tão intenso, que Barata Ribeiro, praticamente terminou sozinho a gestão, administrando a cidade como uma espécie de braço avançado do ministério do Interior, ao qual o Conselho estava submetido.

Portanto, a recepção de Barata Ribeiro não foi muito favorável na cidade, refletindo-se também na imprensa. Primeiramente, por ter sido o último presidente do Conselho de Intendência Municipal, legalmente, estava impedido de ser nomeado prefeito. Tal motivo foi utilizado pelo Senado para vetar sua indicação, tornando-se o único prefeito que teve a nomeação rejeitada pelos senadores da República. Além disso, a forma autoritária com que administrou a

URBANA, ano 2, no 2, 2007, Dossiê: Cidade, Imagem, História e Interdisciplinaridade. 
cidade, quando à frente do Conselho de Intendência Municipal, também deve ter contribuído para essa má recepção, já que se inaugurava uma administração em que a relação entre a Prefeitura e o Legislativo municipal seria fundamental.

Por estar em recesso, o Senado Federal não teve como analisar imediatamente a indicação de Barata Ribeiro para o cargo de Prefeito. Só no ano seguinte o assunto foi discutido entre os senadores.

Em maio de 1893, a Revista Ilustrada apresentou uma série bem humorada de imagens acerca do veto do Senado ao nome de Barata Ribeiro. 0 tema foi abordado em cinco quadros. Num desses quadros, um personagem que oscila entre ser a Revista $^{5}$ e ser um representante da população da cidade aparece não só como narrador, mas também como participante da ação, contemplando a cidade à noite, apoiado numa mureta, e dizendo: "Sabíamos que ela estava no senado, quando à noite fomos surpreendidos por uma musicata de foguetórios, partidos da rua do Ouvidor. Regozijo geral. Liquidaram a barata!". Da elegante rua do Ouvidor escuta-se ecos da fanfarra de fogos em comemoração a rejeição da indicação de Barata Ribeiro ao cargo de Prefeito. 0 último quadro mostra Barata Ribeiro - elegantemente vestido de casaca - saindo da Prefeitura com muitos vetos debaixo dos braços: "Eis aí como saiu quem tantos vetos deu, e que por sua vez foi vetado. Logo 29 - honra e glória!". Nesta última caricatura como prefeito, Barata Ribeiro aparece retratado, ou seja, sem ser representado como inseto.

A imagem de Barata Ribeiro saindo da Prefeitura com vetos debaixo dos braços indica uma gestão que, mesmo tendo sido curta, teve momentos de intenso conflito com os membros do Poder Legislativo municipal. Ao vetar uma resolução do Conselho, o prefeito expunha claramente suas divergências quanto à forma como a casa legislativa tratou determinado assunto. No no 736 da Revista, de junho de 1898, o recurso de caricaturar a ação de vetar foi novamente utilizado para tratar dos embates entre a Prefeitura e o Conselho Municipal.

\footnotetext{
5 O personagem se apresenta como sendo a própria Revista Ilustrada. Trata-se de um figura infantil, caracterizada por Agostini, seu criador, como um personagem da comédia del'arte, do século XV. A figura lembra, por sua roupa de palhaço e atitudes provocativas, cômicas e, as vezes, até grotescas, um espécie de Arlequim ou Polichinelo. Por vezes, o personagem/Revista assume o papel de narrador dos acontecimentos, situando-se fora dos mesmos. Outras vezes, atua diretamente emitindo opinião ou demonstrando sentimentos.
}

URBANA, ano 2, no 2, 2007, Dossiê: Cidade, Imagem, História e Interdisciplinaridade. 


\section{$\Lambda$}

Imagem 3. Revista Ilustrada, no 736, 1898 - FCRB.

No primeiro plano, aparece o então prefeito Ubaldino do Amaral rasgando papéis para jogar no cesto de lixo. Tais papéis/vetos nada mais eram do que resoluções do Legislativo municipal, como as autorizações para extrair loteria, prolongar ruas da cidade e aumentar o preço da carne. No segundo plano, três homens bem vestidos e com narizes grandes - talvez um sinal de bisbilhotice -, sob o portal do gabinete do prefeito, olham sorrateiramente a ação de Ubaldino. A linguagem visual sintetiza-se na legenda: "O ilustre Dr. Ubaldino, apesar dos seus vetos e boas intenções, está sofrendo uma guerra que o irrita bastante e que não sabemos no que dará...".

URBANA, ano 2, no 2, 2007, Dossiê: Cidade, Imagem, História e Interdisciplinaridade. 
A gestão de Ubaldino do Amaral, empossado logo após o atentado fracassado à vida de Prudente de Morais, foi caracterizada por uma relação difícil com os membros do Conselho Municipal, de intenso conflito.

A Revista Ilustrada também foi muito rica na produção de cenas cômicas versando sobre o antes, o durante e o depois das eleições municipais, constituindo-se numa fonte rica e rara para uma melhor compreensão desse tipo de pleito. Através de seus números é possível acompanhar versões bem humoradas das eleições para as três legislaturas iniciais do Conselho Municipal. Vejamos as eleições para a Segunda legislatura (1895-1896).

Em dezembro de 1894, o oo 671 trouxe em sua última página uma charge sobre a campanha eleitoral. Três homens bem vestidos - candidatos ao Conselho Municipal - pedem votos a possíveis eleitores da cidade. A ação transcorre na rua e um dos eleitores deposita o voto numa espécie de chapéu/urna. A legenda que sintetiza a moral da história é primorosa: "- Pra cera do Santíssimo! Pra missa das almas! Um votinho pelo amor de Deus! - Pois não... você promete tanta coisa! Vamos a ver..."

URBANA, ano 2, no 2, 2007, Dossiê: Cidade, Imagem, História e Interdisciplinaridade. 


\section{$\Lambda$}

Imagem 4. Revista Ilustrada, no 671, 1894 - FCRB.

Pela legenda, é óbvio o estabelecimento de relações entre a campanha eleitoral - figurada como um ato de pedir votos na rua, tentando angariar eleitores - e a prática cultural religiosa do peditório. Desde os tempos coloniais, irmandades saíam pelas ruas da cidade do Rio de Janeiro pedindo esmolas com vistas a angariar fundos em favor das festividades religiosas. A prática do peditório manteve-se presente na cidade durante todo o período imperial. Martha Abreu (1999:47-64) mostra bem as características dessa prática de recolher donativos no caso da festa do Divino Espírito Santo. Para as festividades do

URBANA, ano 2, no 2, 2007, Dossiê: Cidade, Imagem, História e Interdisciplinaridade. 
Divino, pessoas saíam em grupos, levando a bandeira da irmandade e uma bandeja para recolher as esmolas. Tudo indica que a prática do peditório também esteve presente nos tempos iniciais da República, podendo então ser utilizada como referência humorística do ato de pedir votos. Por sinal, ela também é utilizada em músicas, como a de Chiquinha Gonzaga, com letra de Arthur Azevedo:

Em nome da Irmandade

Eu ando sem cessar, por toda essa cidade esmola a tirar!

E profissão tão nobre Não deixo nem a pau, pois rende muito cobre o velho balandrau!

Este emprego de sacola

Sim, senhor, é rendosíssimo

Esmola, esmola, esmola

Para a cera do Santíssimo!...

(GONZAGA e AZEVEDO apud ABREU, 1999:249)

No caso, pode-se dizer que os candidatos também não queriam se afastar de "profissão tão nobre" e corriam sua sacola de pedintes de voto, oferecendo promessas e mais promessas para céticos eleitores.

Já o no 672, de janeiro de 1895, traz na última página uma caricatura ironizando a quantidade de candidatos para ocupar as poucas cadeiras do Conselho Municipal. Num grande salão, de um lado perfilam-se cadeiras vazias (representando as vagas em disputa), do outro lado, vários homens bem vestidos (todos trajando casacas, exceto um, vestido com hábito monástico), certamente candidatos, alguns com mãos estendidas e direcionadas a uma grande urna que está ao centro. De fora do salão, ainda é possível ver uma fila de pessoas que não conseguiram entrar. O personagem que representa a visão crítica da Revista, no canto direito, com as mãos nos joelhos, com as pernas meio flexionadas, participa da ação rindo do que vê. Mais uma vez, a legenda reforça a linguagem visual: "Tantos candidatos para essas 15 cadeiras da Intendência. Dois mil trezentos e sessenta e nove que se apresentam, muitos têm de ficar de pé, ou... sentados no chão".

URBANA, ano 2, no 2, 2007, Dossiê: Cidade, Imagem, História e Interdisciplinaridade. 


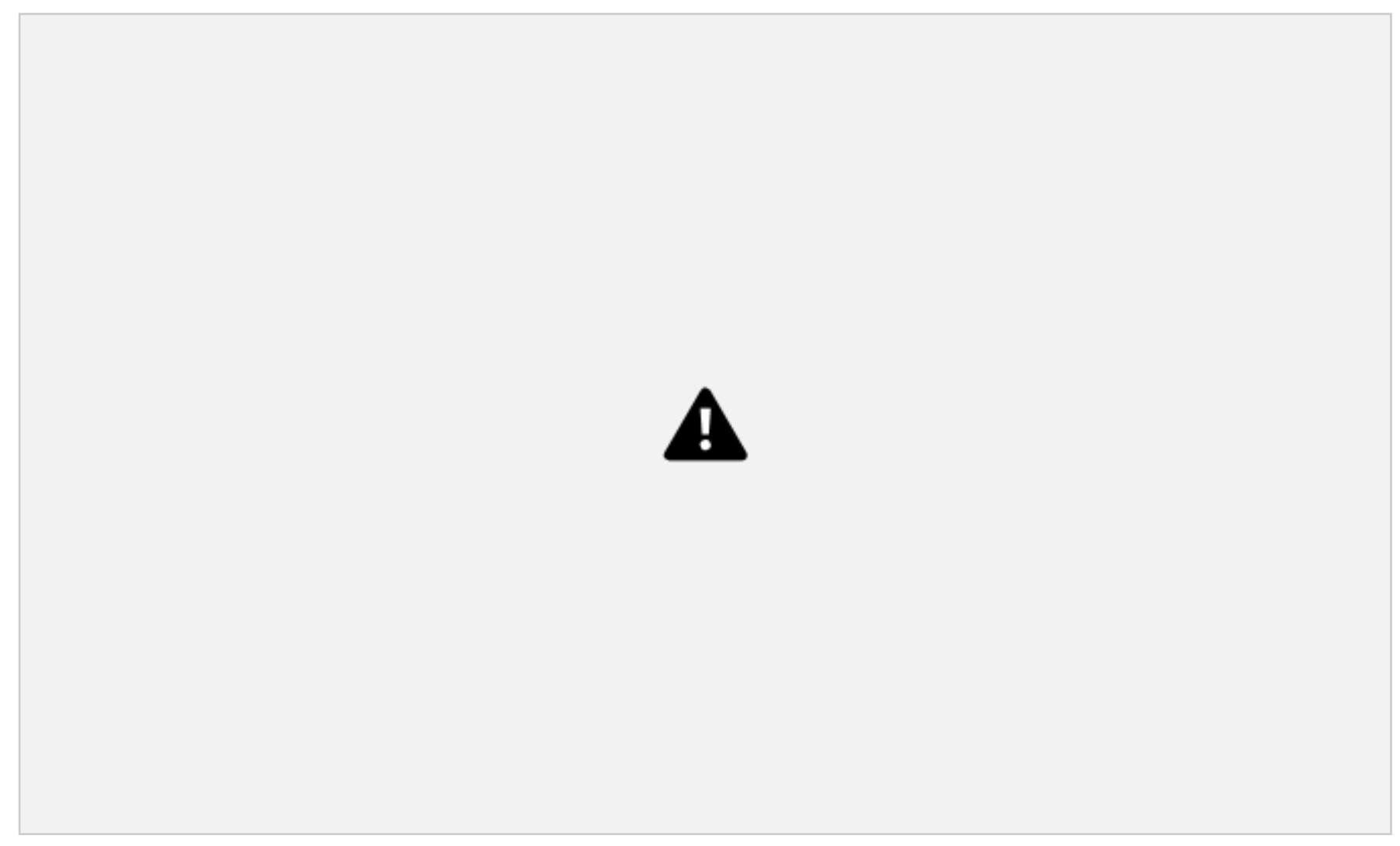

Imagem 5. Revista Ilustrada, no 672, 1895 - FCRB.

No número 673, ainda no mês de janeiro, a eleição municipal assume a capa da Revista Ilustrada, o que é indicador de importância e também popularidade do evento. Tal qual o número anterior, a Revista continua a criticar o considerável número de candidatos, o que impossibilitava os eleitores de obter informações sobre todos eles. Isso gerava a entrada de intendentes por vezes pouco conhecidos por parte da população da cidade. Tal crítica foi feita traçando um paralelo entre o momento de abrir as urnas para conferir o resultado da eleição e o momento da folia de momo, que se aproximava. No primeiro plano da caricatura, existe uma urna ao centro e pessoas mascaradas e fantasiadas - os candidatos eleitos - saindo da urna. Esse plano se completa com uma chuva de votos, parecendo confetes, numa clara alusão à folia de momo. Ao fundo, num segundo plano, existe um conjunto de pessoas - provavelmente os candidatos perdedores - que parecem estar brigando, tentando entrar na intendência. De toda forma, a eleição é figurada como uma festa carnavalizada, cheia de surpresas, disputas, alegrias e tristezas.

URBANA, ano 2, no 2, 2007, Dossiê: Cidade, Imagem, História e Interdisciplinaridade. 
A linguagem visual da Revista atribuía significação à política formal, traduzindo-a - no sentido de criação - para seus leitores que eram também moradores da cidade e possíveis eleitores. Tal tradução procurava relacionar as práticas da política formal com as práticas culturais caras a grande parte da população da cidade, tais como as festividades religiosas e a folia de momo.

Além das "crônicas visuais" sobre as eleições municipais, as nomeações dos prefeitos e os vetos às resoluções do Conselho, na Revista Ilustrada é possível encontrar uma riquíssima produção de imagens que diziam respeito aos problemas da política ordinária, do cotidiano da cidade.

\section{Viver no Rio de Janeiro: imagens da política ordinária}

A falta d'água, o preço da carne fresca e a prática dos jogos de azar eram os alvos privilegiados do humor visual da Revista Ilustrada. Os demais problemas da cidade, de certa forma, podem ser agrupados a partir dos três temas citados.

Entre 1892 e 1898, a Revista Ilustrada produziu uma série de caricaturas tratando do intenso calor por que passava a cidade no período do verão, em que os problemas do alagamento das ruas, dos surtos epidêmicos e da falta d'água foram retratados. Nessas caricaturas existe a intensa participação do personagem que simboliza a Revista, não só narrando os acontecimentos na cidade, como também, atuando diretamente como qualquer cidadão.

Em diversos números da Revista, quase sempre entre os meses de dezembro e abril, encontramos situações em que o personagem reclamava muito do calor e, ao mesmo tempo, tomava alguma atitude - por vezes fracassada para dirimir a sensação desagradável que a temperatura elevada the provocava. O ano de 1895 é rico em tais situações. Em março, por exemplo, nos dois quadros do no 679, temos, primeiramente, o personagem com seus instrumentos de trabalho - o bico de pena e a pasta com papéis - correndo sobre um chão escaldante - representado por uma fogueira - e suando muito; logo depois, o personagem aparece dando um mergulho na baia de Guanabara, tendo o Pão de Açúcar ao fundo.

URBANA, ano 2, no 2, 2007, Dossiê: Cidade, Imagem, História e Interdisciplinaridade. 
Imagem 6. Revista Ilustrada, no 679, 1895 - FCRB.

Na última página do no 683, de abril de 1895, a Revista retrata em um dos quadros o alagamento de uma rua da cidade, provocado por chuvas intensas. A cena é composta por várias ações. Do lado esquerdo, uma mulher encontra-se de pé num móvel, tentando se proteger da água que invadiu a casa. Do lado direito, com capas e guarda-chuvas, homens andam pelas ruas alagadas. No centro, ao fundo, vários passageiros estão no teto de um bonde parado pelo alagamento e, à frente, o personagem/Revista está nadando e narrando o fato.

URBANA, ano 2, no 2, 2007, Dossiê: Cidade, Imagem, História e Interdisciplinaridade. 
Imagem 7. Revista Ilustrada, № 638, 1895 - FCRB.

Além dos alagamentos provocados pelas chuvas torrenciais, as reclamações sobre o intenso calor da cidade, feitas pelo personagem, abriam espaço para criticar o serviço de abastecimento de água. Por vezes, o personagem encontrava-se na situação de precisar se refrescar do calor. Porém, exatamente nessa hora, deparava-se com a falta d'água, como no caso do no 656 da Revista, de fevereiro de 1893. A história é contada em três quadros. No primeiro, temos a Revista suando muito. No quadro seguinte, o personagem, segurando um termômetro e continuando a suar muito, encontra-se numa posição de espanto. Por fim, vestido com um roupão, meio que surpreendido, depara-se com os poucos pingos saídos da torneira responsável por alimentar a banheira de água.

URBANA, ano 2, no 2, 2007, Dossiê: Cidade, Imagem, História e Interdisciplinaridade. 
Imagem 8. Revista Ilustrada, no 656, 1893 - FCRB.

O fato de o personagem aparecer reclamando do calor da cidade e agindo para minimizá-lo era, provavelmente, uma forma eficaz de construção de empatia entre a Revista e os seus leitores. Com isso, ela sinalizava que os problemas ocasionados pelo intenso calor do verão eram compartilhados por todos, tanto pelo personagem, como pelos habitantes da cidade. Ou melhor, o personagem deveria ser compreendido como a fala da Revista e, ao mesmo tempo, dos moradores da cidade.

A Revista Ilustrada também produziu uma série de caricaturas retratando a carestia existente na cidade do Rio de Janeiro do final do século XIX. O alto preço dos aluguéis e dos alimentos - em especial, da carne fresca - foram os alvos principais de seu traço. Em dezembro de 1895, a questão dos aluguéis, tão cara a uma parte significativa da população da cidade, foi tratada no no 704 . A cena é composta por duas ações simultâneas. A primeira consiste em inquilinos ajoelhados e com os braços e cabeças direcionados para o alto - como se rezassem -, olhando para uma casa suspensa por uma corda presa à lua. Por sua vez, existe a ação de dois proprietários puxando cada vez mais essa corda para o alto. A legenda ajuda a unificar as ações, completando a denúncia

URBANA, ano 2, no 2, 2007, Dossiê: Cidade, Imagem, História e Interdisciplinaridade. 
realizada pela imagem: "Os Srs. proprietários elevam os aluguéis das casas à altura de um princípio, e parece quererem atingir os córneos da lua. Arre! que é muita ganância! Passa fora, agiotas!"

Imagem 9. Revista Ilustrada, no 704, 1895 - FCRB.

Além do alto preço dos aluguéis, a carestia dos alimentos básicos utilizados por grande parte da população da cidade também foi retratada em caricaturas. No no 736 , de junho de 1898, um homem pobre - tipo maltrapilho, com as roupas rasgadas - olha para a vitrine de uma loja onde se lê: "artigos de luxo". Nela encontram-se expostos relógios, jóias, belas camisas, sedas e, ao mesmo tempo, feijão, arroz, carvão em pedra, queijos, goiabada, carne seca etc. A legenda dá o tom do elevado preço dos alimentos à época: "Atualidade

URBANA, ano 2, no 2, 2007, Dossiê: Cidade, Imagem, História e Interdisciplinaridade. 
financeira e nada econômica. Os gêneros de primeira necessidade rivalizam em preço com as jóias e tornam-se verdadeiros objetos de luxo. Para quem apelar?"

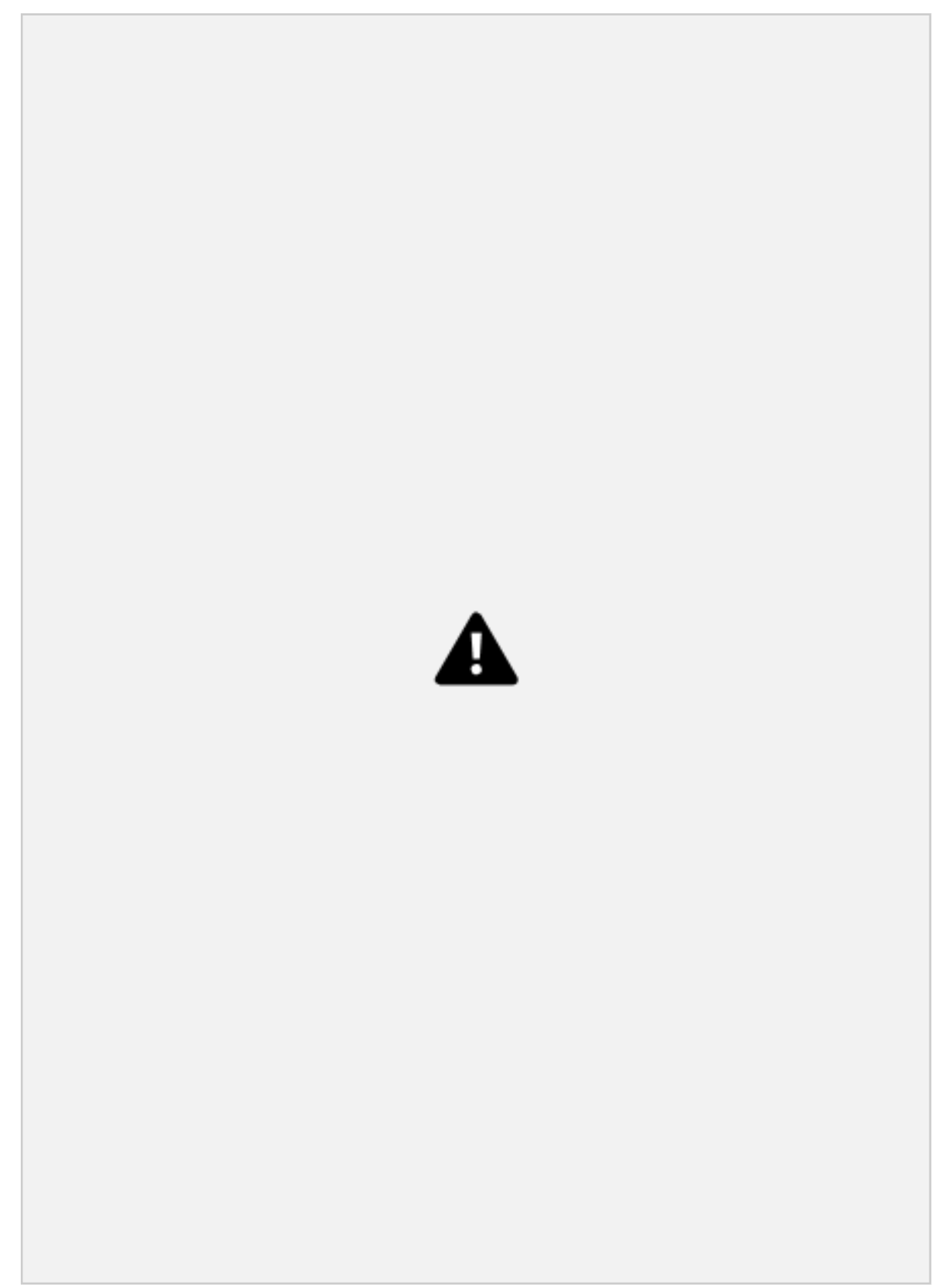

Imagem 10. Revista Ilustrada, № 736, 1898 - FCRB.

Dentre os alimentos, não há dúvidas de que a Revista deu um grande destaque à questão do preço da carne fresca. Entre 1892 e 1898, existiram muitas caricaturas versando sobre o abastecimento de carne. No no 655 , de janeiro de 1893, a Revista trouxe a cena de um açougue com diversas carnes penduradas, trazendo afixadas o valor de mil e duzentos réis por quilo. Do lado

URBANA, ano 2, no 2, 2007, Dossiê: Cidade, Imagem, História e Interdisciplinaridade. 
direito, temos o açougueiro cortando um pedaço de carne e do lado esquerdo, temos um homem - muito bem vestido, por sinal -, numa posição de surpresa frente ao preço.

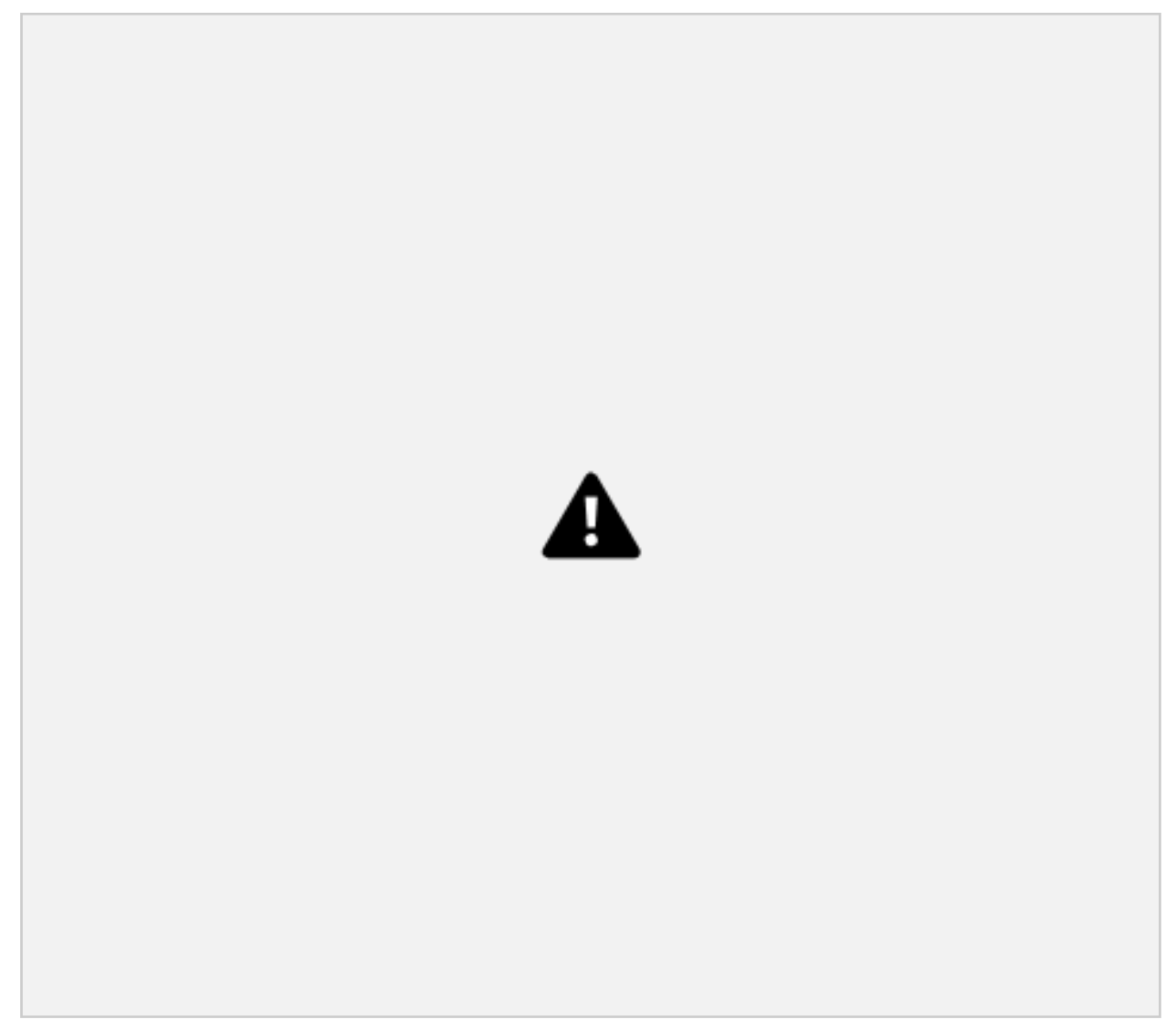

Imagem 11. Revista Ilustrada, no 655, 1893 - FCRB.

Outro tema de grande destaque dentre as imagens da Revista Ilustrada, entre 1892 e 1898, não mais referente à carestia, foi o combate a qualquer tipo de jogo de azar, em especial, ao "jogo dos bichos", assim denominado à época. Através de uma série de caricaturas, a Revista posicionava-se muito claramente sobre esse assunto, defendendo que os poderes públicos - em especial, a polícia - reprimissem os jogos de azar na cidade.

As caricaturas oscilavam entre a denúncia da quantidade de jogos diferentes oferecidos à população da cidade e a da impunidade que pairava sobre a prática de apostar. Em dezembro de 1895, no no 702, trouxe a crítica em relação ao número de jogos oferecidos nas ruas da cidade. A caricatura tratava da diversidade de loterias. A venda dos bilhetes acabava importunando o andar

URBANA, ano 2, no 2, 2007, Dossiê: Cidade, Imagem, História e Interdisciplinaridade. 
pela cidade. Homem e mulher, bem vestidos, andam pela rua com certa dificuldade, devido à chuva de bilhetes de loteria. A legenda sintetiza bem o desconforto de ambos: "Atualmente, quem sai à rua vê-se perseguido por essa centena de joguinhos, sem falar nas roletas e nos contos do vigário, que tornam-se nesta Capital uma epidemia reinante. Quando acabaremos com esta vergonhosa jogatina? Que venham também uns trezentos contos para a extinção deste micróbio tão maléfico como o da amarela."

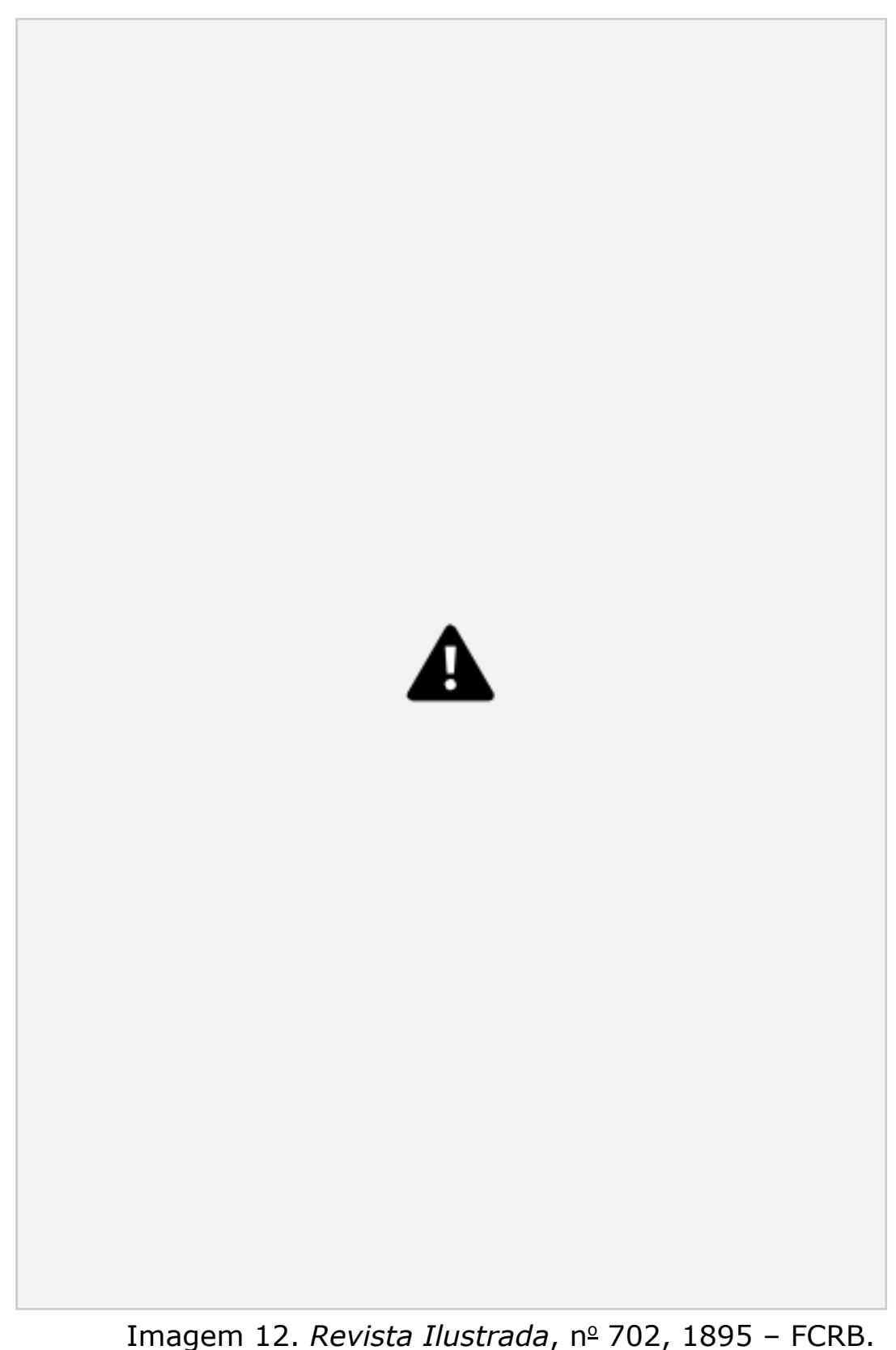

URBANA, ano 2, no 2, 2007, Dossiê: Cidade, Imagem, História e Interdisciplinaridade. 
O jogo era visto pela Revista como um grande mal que assolava a população da cidade. Era comum fazer paralelos com a imagem da doença, do micróbio, de algo que invade e pode matar. Por isso, os pedidos constantes da Revista para a polícia atuar na repressão aos jogos de azar.

O cotidiano da cidade foi retratado e criticado através das imagens presentes na Revista Ilustrada. Um cotidiano que priorizava os problemas enfrentados quase que diariamente por parte de seus habitantes, como a falta d'água, os surtos epidêmicos, a elevação do valor dos aluguéis, o alto preço da carne bovina e dos demais alimentos, a presença dos jogos de azar etc.

Problemas que também estavam presentes na coluna "Queixas do Povo", do Jornal do Brasil, e nos requerimentos, nos abaixo-assinados, nas representações e nas petições encaminhadas à casa legislativa municipal. Além disso, apareciam sob a forma de resposta mais própria do Conselho Municipal a todas essas demandas, ou seja, eram as matérias de muitos projetos de lei. Logo, as imagens da Revista Ilustrada sobre essa outra faceta da política municipal - os problemas que afligiam a população cotidianamente - ajudam a pensar o quanto o Conselho Municipal e a população da cidade encontravam formas de expressão e comunicação. Entre 1892 e 1902, o Legislativo municipal, longe de pairar no ar, nada mais fez do que discutir esses problemas da cidade, por vezes tomando decisões que agradavam a uns e desagradavam a outros grupos, mas sempre estabelecendo um diálogo entre o Conselho e a cidade.

\section{Referências Bibliográficas:}

ABREU, Martha (1999). O império do Divino: festas religiosas e cultura popular no Rio de Janeiro, 1830-1900. Rio de Janeiro: Nova Fronteira; São Paulo: Fapesp.

ALBERNAZ, Maria Paula (1985). As vilas: uma contribuição à história da arquitetura popular através do estudo do espaço urbano. Rio de Janeiro: PUR-UFRJ, dissertação de Mestrado.

URBANA, ano 2, no 2, 2007, Dossiê: Cidade, Imagem, História e Interdisciplinaridade. 
BASTOS, Ana Marta Robrigues (1984). O Conselho de Intendência Municipal: autonomia e instabilidade (1889-1892). Rio de Janeiro: CEH-FCRB.

BELluZzo, Ana Maria de Moraes (1992). A tradição da caricatura no Brasil e Angelo Agostini. In: Voltolino e as raízes do modernismo. São Paulo: Marco Zero. BENCHIMOL, Jaime Larry (1992). Pereira Passos: um Haussmann tropical. A renovação urbana da cidade do Rio de Janeiro no início do século XX. Rio de Janeiro: Secretaria Municipal de Cultura, Turismo e Esportes, Departamento Geral de Documentação e Informação Cultural, Divisão de Editoração.

BODSTEIN, Regina Cele de Andrade (1984). Condições de saúde e prática sanitária no Rio de Janeiro (1880-1900). Niterói: PPGH-UFF, dissertação de Mestrado.

CARVALHO, Delgado de (1990). História da cidade do Rio de Janeiro. Rio de Janeiro: Secretaria Municipal de Cultura, Departamento Geral de Documentação e Informação Cultural.

CARVALHO, José Murilo de (1987). Os bestializados: o Rio de Janeiro e a República que não foi. Rio de Janeiro: Companhia das Letras.

CARVALHO, Lia de Aquino (1995). Contribuições ao estudo das habitações populares: Rio de Janeiro: 1866-1906. Rio de Janeiro: Secretaria Municipal de Cultura, Departamento Geral de Documentação e Informação Cultural.

ELIA, Francisco Carlos da Fonseca (1984). A questão habitacional no Rio de Janeiro da Primeira República: 1889-1930. Niterói: PPGH-UFF, dissertação de Mestrado.

GANTOS, Marcelo Carlos (1993). Processo e crise urbana: a Comissão de Melhoramentos da cidade do Rio de Janeiro (1870-1876). Niterói: PPGH-UFF, dissertação de Mestrado.

LAMARÃO, Sérgio Tadeu de Niemeyer (1991). Dos trapiches ao porto: um estudo sobre a área portuária do Rio de Janeiro. Rio de Janeiro: Secretaria Municipal de Cultura, Turismo e Esportes, Departamento Geral de Documentação e Informação Cultural, Divisão de Editoração.

LIMA, Herman (1963). História da caricatura no Brasil, 4 vols. Rio de Janeiro: José Olympio.

LUSTOSA, Isabel (2003). O texto e o traço: a imagem de nossos primeiros presidentes através do humor e da caricatura. In: FERREIRA, Jorge e DELGADO, Lucília de Almeida Neves (Org.). O tempo do liberalismo excludente: da

URBANA, ano 2, no 2, 2007, Dossiê: Cidade, Imagem, História e Interdisciplinaridade. 
Proclamação da República à Revolução de 1930. Rio de Janeiro: Civilização Brasileira.

MAGALHÃES, Marcelo de Souza (2004). Ecos da política: a capital federal, 1892-1902. Niterói: PPGH-UFF, tese de Doutorado.

MAGALHÃES, Marcelo de Souza (2007). Calçamentos e batatas: o Conselho Municipal e a cidade (capital federal, 1892-1902). In: ABREU, Martha, SOIHET, Rachel e GONTIJO, Rebeca (Org.). Cultura política e leituras do passado: historiografia e ensino de história. Rio de Janeiro: Civilização Brasileira.

REIS, José de Oliveira (1977). O Rio de Janeiro e seus prefeitos. Rio de Janeiro: Prefeitura da Cidade do Rio de Janeiro.

RIBEIRO, Marcus Tadeu Daniel (1988). Revista Ilustrada (1876-1898), síntese de uma época. Rio de Janeiro: PPGHIS-UFRJ, dissertação de Mestrado.

ROCHA, Oswaldo Porto (1995). A era das demolições: cidade do Rio de Janeiro: 1870-1920. Rio de Janeiro: Secretaria Municipal de Cultura, Departamento Geral de Documentação e Informação Cultural.

SALIBA, Elias Thomé (2002). Raízes do riso: a representação humorística na história brasileira: da Belle Époque aos primeiros tempos do rádio. São Paulo: Companhia das Letras.

SANTOS, Francisco Agenor Noronha (1945). Acerca da organização municipal e dos prefeitos do Distrito Federal. Rio de Janeiro: Oficinas Gráficas O Globo.

SCHWARCZ, Lilia Moritz (2000). As barbas do imperador: D. Pedro II, um monarca nos trópicos. São Paulo: Companhia das Letras.

SILVA, Eduardo (1988). As queixas do povo. Rio de Janeiro: Paz e Terra.

SILVA, Marcos Antônio da (1990). Caricata República: Zé Povo e o Brasil. São Paulo: Marco Zero.

TEIXEIRA, Luiz Guilherme Sodré (2001). O traço como texto: a história da charge no Rio de Janeiro de 1860 a 1930. Rio de Janeiro: FCRB.

VAZ, Lílian Fessler (1985). Contribuição ao estudo da produção e transformação do espaço da habitação popular; as habitações coletivas no Rio Antigo. Rio de Janeiro: PUR-UFRJ, dissertação de Mestrado.

VELLOSO, Monica Pimenta (1996). Modernismo no Rio de Janeiro: turunas e quixotes. Rio de Janeiro: Editora FGV.

WEID, Elisabeth von der (1984). O prefeito como intermediário entre o poder federal e o poder municipal na Capital da República. Rio de Janeiro: CEH-FCRB.

URBANA, ano 2, no 2, 2007, Dossiê: Cidade, Imagem, História e Interdisciplinaridade. 
Texto recebido em: 01/10/2007.

URBANA, ano 2, no 2, 2007, Dossiê: Cidade, Imagem, História e Interdisciplinaridade. CIEC/UNICAMP 